\title{
Manual de los Reglamentos del Agua en Florida: Regulaciones de Descargas en Aguas Subterráneas a Nivel Estatal1
}

Michael T. Olexa, Luke D'Isernia, Laura Minton, Dulcy Miller y Sara Corbett ${ }^{2}$

\section{Prefacio}

Este manual esta diseñado para proporcionar un resúmen autorizado, exacto y actual de las principales leyes Federales y de Florida que están directa o indirectamente relacionadas a la agricultura. Este manual debe proveer una vista general de los muchos derechos y responsabilidades que tienen los agricultores y propietarios de tierras agrícolas bajo las leyes tanto Federal como de Florida, así como también la información de los contactos apropiados para obtenerla con más detalle. Sin embargo, el lector debe estar advertido de que algunas partes de esta publicación podrían volverse obsoletas en cualquier momento, debido a que las leyes, reglas administrativas, y decisiones de la corte, sobre las cuales se basa este manual, se encuentran bajo revisión constante. Algunos detalles de las leyes citadas no se mencionan, debido a limitaciones de espacio.
Este manual es distribuido con la aclaración de que los autores no intentan proporcionar una asesoría legal o profesional, y que la información contenida aquí no debe ser considerada como un sustituto de asesoría profesional. En este manual, no se incluye toda la información para llevar a cabo el cumplimiento de las leyes Federales y de Florida y los reglamentos que rigen la protección del agua. Por estas razones, el uso de estos materiales por cualquier persona, constituyen un acuerdo para mantener libre de perjuicios a los autores, al Servicio de Extensión Cooperativa de Florida, al Instituto de los Alimentos y Ciencias Agrícolas y a la Universidad de Florida por reclamos de responsabilidad, daños o gastos provenientes de quien sea, por haberse referido o basado en la información contenida en este manual.

1. Este es el documento EDIS FE084, una publicación de Food and Resource Economics Department, Florida Cooperative Extension Service, Institute of Food and Agricultural Sciences, University of Florida, Gainesville, FL. Publicado Noviembre 2006. Por favor visite la página electrónica de EDIS en http://edis.ifas.ufl.edu.

2. Michael T. Olexa, profesor, Food and Resource Economics Department y director, Agricultural Law Center, University of Florida, Gainesville, FL, y presidente, Agricultural Law Committee, The Florida Bar; Luke D'Isernia, alumni, Levin College of Law, University of Florida, Gainesville, FL; Laura Minton, abogado, Dean, Mead, Egerton, Bloodworth, Capouano y Bozarth, PA, Orlando FL; Dulcy Miller, abogado, Foley and Lardner, LLP, Orlando, FL; y Sarah Corbett, abogado, Florida Second District Court of Appeal, Lakeland, FL. La traducción del ingles al español estuvo a cargo de Filiberto Reyes-Villanueva.

EI Instituto de Alimentos y Ciencias Agrícolas es un empleador que opera bajo Acción Afirmativa y provee Oportunidades Igualitarias, autorizado a proveer investigación, información educativa y otros servicios, únicamente a los individuos e instituciones que operan sin discriminación alguna con relación al credo, color, religión, edad, incapacidad, sexo, orientación sexual, estado civil, nacionalidad, opinion política o afiliaciones. Para más información sobre como obtener otras publicaciones de extensión, comuníquese con la oficina de Servicio de Extensión de su condado. Servicio de Extensión de la Florida / Instituto de Alimentos y Ciencias Agrícolas / Universidad de la Florida / Larry Arrington, Decano. 


\section{¿Cómo Regula Florida las Descargas de Aguas Suberráneas?}

Florida regula la descarga de aguas subterráneas por dos métodos:

1. La Descarga de desecho en las aguas del estado esta prohibida, a menos que sea permitida por una agencia del estado. Ya que el agua subterránea esta incluida en la definición de agua, ésta también se aplica al agua subterránea. Una actividad de descarga no será permitida si los contaminantes reducen la calidad del suelo o del agua superficial de acuerdo a la clasificación estándar requerida por el Departamento de Protección Ambiental (APA). Un contaminante es cualquier sustancia que es dañina a la vida de las plantas o los animales.

\section{La Aplicación de químicos esta exento para el} control de insectos y maleza acuática para propósitos agrícolas. Sin embargo, los químicos deben ser aprobados para el uso particular de la Agencia de Protección Ambiental (APA) o el Departamento de Agricultura y Servicios al Consumidor (DASC). La aplicación debe realizarse de acuerdo a las etiquetas y estándares del estado, así como la primera parte de la Ley de Plaguicidas de Florida (Capitulo 487, de los Estatutos de Florida).

\section{¿Cuáles Son las Clasificaciones de las Aguas Subterráneas?}

Las aguas subterráneas se clasifican en cinco categorías (Clase F-1, G-1, G-2, G-3, G-4) basadas primero en si el agua es potable (tomable) o no potable, y después sobre el total de sólidos disueltos que contiene el agua y si están localizadas en acuíferos confinados o no confinados [FAC 62-520.410(1)]. De acuerdo al esquema de clasificación, la Clase F-1, son aguas potables, las aguas subterráneas en una sola fuente acuífera, la cual tiene un contenido de sólidos totales menor de $3,000 \mathrm{mg} / 1$ y fue específicamente reclasificado como Clase F-1 por la Comisión de Regulación del Medio Ambiente (CRMA). Los ejemplos de las aguas F-1 incluyen los acuíferos superficiales en noreste del Condado Flagler. Los acuíferos (formaciones geográficas que suministran el agua subterránea a los pozos, manantiales o aguas superficiales) se quedan con la más alta protección y son conocidos como las aguas G-1. Las aguas de las Clases G-4 son aguas no potables, localizadas solamente en los acuíferos confinados, y reciben la mínima cantidad de protección. El agua subterránea no confinada recibe siempre más protección ya que es susceptible a contaminación de otro acuífero.

Los estándares de calidad del agua subterránea incluyen lo siguiente:

- Criterio Mínimo. Requiere que todas las aguas subterráneas no deben estar contaminadas por descargas de sustancias toxicas o carcinogénicas

- Contaminante Máximo. Este estándar representa la cantidad máxima de contaminantes particulares que serán tolerados en una clase de agua particular. Los niveles máximos de contaminante (Estándares Primarios de Agua Potable) están generalmente en acuerdo con los estándares de la APA contenidas en la Ley Federal del Agua Potable Segura. Cuando el máximo de los niveles de contaminantes sean excedidos por una actividad de descarga, los permisos no serán emitidos, según el Capitulo 403, de los Estatutos de Florida, Secciones 403.088 .

Los estándares secundarios también son monitoreados en las nuevas instalaciones para el cumplimiento. Las instalaciones existentes están exentas de monitoreo y cumplimiento con los estándares secundarios.

De acuerdo al Capitulo 403, de los Estatutos de Florida, Sección 403.087, se requieren los permisos de descarga para las instalaciones estacionarias (las estructuras que pueden echar contaminantes al agua en cantidades prohibidas por las reglas). Los sistemas de manejo de las aguas agrícolas están exentos de este requerimiento según el Capitulo 403, de los Estatutos de Florida, Sección 403.927 (2); pero son reguladas según el Capitulo 373 de los Estatutos de Florida, Sección 373.019. Sin embargo, el ultimo punto de descarga esta regulado aun por el DPA. Posteriormente, el agricultor puede ser responsable 
cuando una actividad agrícola contamina los cuerpos de agua fuera del sistema o cuando el agua subterránea esta contaminada debido a una filtración la cual causa la contaminación de puntos distantes en el acuífero.

Los Distritos para el Manejo del Agua (DMA) tienen el poder para el control de los usos de consumo del agua subterránea en las áreas de contaminación conocidas de esas aguas. En otras palabras, a través del Capitulo 373, de los Estatutos de Florida, Secciones 373.036 - 0698, los DMAs pueden restringir a través de permisos, el uso de consumo cuando es encontrada una contaminación.

\section{¿Las Descargas de Agua Subterránea Incluyen el Agua de Desagüe de las Lluvias?}

El agua de desagüe de las lluvias, es agua que fluye fuera de la tierra en las corrientes y el suelo después de una tormenta de lluvia. Esta agua de lluvia es frecuentemente contaminada con los productos químicos usados en la tierra por la cual corre.

La APA regula las descargas del agua de lluvia asociada con la agricultura. Al momento de la publicación, la APA exime de los permisos las descargas de agua de lluvia de origen agrícola y los flujos de retorno agrícolas compuestos en su totalidad por el flujo de retorno de las áreas de irrigación. Sin embargo, la APA no exime los flujos de retorno agrícola que no están compuestos en su totalidad de los flujos de retorno de irrigación agrícola. Por ejemplo, una acequia conteniendo fertilizantes o plaguicidas que entra en los canales de aguas navegables, esta sujeta a los requerimientos de permiso de la Ley del Agua Limpia. La APA tiene requisitos estrictos del desagüe de las aguas de lluvia para la escorrentía industrial y municipal.

Es importante anotar también, que los edificios de una estructura (graneros, establos etc.) que perturban más de un acre de suelo (excavación de cimientos, construcciones, apilamientos, etc.) necesitan de un permiso de aguas de lluvias, pero solamente para la fase de construcción activa. Una vez que la construcción es terminada, el permiso se termina.

\section{¿Cuáles Son los Requerimientos del Permiso?}

Generalmente, los permisos serán emitidos solamente cuando un solicitante pueda establecer que la actividad o instalación en cuestión no degradará las aguas recibidas, bajo los estándares aplicables. Los resultados de las pruebas y la instalación del equipo de control de contaminación son requeridos frecuentemente para garantizar tales reclamos. El gravamen de las pruebas de derecho para un permiso recae en quien hace la aplicación.

En sus reglas, el DPA estipula explícitamente que las consideraciones de descarga de aguas subterráneas están siendo incorporadas en los requisitos del permiso existente. El propósito principal de esa regla es prohibir las descargas en las aguas subterráneas, donde dicha descarga causa una violación de los estándares de calidad del agua y el criterio mínimo de las aguas subterráneas. Sin embargo, una zona de descarga (también conocida como una zona de mezcla) puede ser establecida por un permiso o por una regla. Una zona de descarga es un área tri-dimensional predefinida en el suelo alrededor de una instalación, donde muchos estándares de calidad del agua subterránea primarios y secundarios no se aplican, y los efluentes tienen una oportunidad para difundir o degradar algo, antes de dejar los límites de la zona de descarga.

Las cuatro actividades que están actualmente exentas de los requisitos de los permisos son:

1. Campos agrícolas.

2. Acequias y canales.

3. Lagunas de desecho de ganado (aquellos usados en grandes establos necesitan de permiso; los pequeños y medianos establos están actualmente en procesos de reglamentación en el DPA).

4. Las instalaciones de agua de lluvia (se aplican limitaciones especiales).

Concerniente a las fuentes contaminación de no punto del agua de las cuatro actividades agrícolas mencionadas arriba, el DPA regula al estado que 
cuando las descargas de esos cuerpos de agua (ej; canales y lagunas) alcancen aguas comunes (ej., ríos, lagos y agua subterránea) los estándares se incrementan para los plaguicidas residuales y otros contaminantes. Esta regla requiere la eliminación de las exenciones y exige un permiso cuando una actividad es causa de contaminación. También, la contaminación de las aguas comunes puede resultar en castigos criminales y civiles. Los agricultores pueden ganar los mejores resultados siguiendo las Prácticas de Mejor Manejo para aliviar esos problemas

\section{Agradecimientos}

Los autores agradecen al personal de las agencias estatales y federales por su tiempo y asesoría en la preparación de este manual. Los autores agradecen especialmente a Richard Budell del Office of Agricultural Water Policy of the Florida Department of Agriculture and Consumer Services por el apoyo económico para el desarrollo de esta publicación. 